Article

\title{
Water Body Distributions Across Scales: A Remote Sensing Based Comparison of Three Arctic Tundra Wetlands
}

\author{
Sina Muster ${ }^{1, *}$, Birgit Heim ${ }^{1}$, Anna Abnizova ${ }^{2}$ and Julia Boike ${ }^{1}$ \\ ${ }^{1}$ Alfred Wegener Institute Helmholtz Centre for Polar and Marine Research, Telegrafenberg A43, \\ 14473 Potsdam, Germany; E-Mails: birgit.heim@awi.de (B.H.); julia.boike@ awi.de (J.B.) \\ ${ }^{2}$ Geography Department, York University, Toronto, ON M3J 1P3, Canada; \\ E-Mail: anna_abnizova@yahoo.ca \\ * Author to whom correspondence should be addressed; E-Mail: sina.muster@awi.de; \\ Tel.: +49-331-288-2204.
}

Received: 30 January 2013; in revised form: 11 March 2013 / Accepted: 12 March 2013 /

Published: 25 March 2013

\begin{abstract}
Water bodies are ubiquitous features in Arctic wetlands. Ponds, i.e., waters with a surface area smaller than $10^{4} \mathrm{~m}^{2}$, have been recognized as hotspots of biological activity and greenhouse gas emissions but are not well inventoried. This study aimed to identify common characteristics of three Arctic wetlands including water body size and abundance for different spatial resolutions, and the potential of Landsat-5 TM satellite data to show the subpixel fraction of water cover (SWC) via the surface albedo. Water bodies were mapped using optical and radar satellite data with resolutions of $4 \mathrm{~m}$ or better, Landsat-5 TM at $30 \mathrm{~m}$ and the MODIS water mask (MOD44W) at $250 \mathrm{~m}$ resolution. Study sites showed similar properties regarding water body distributions and scaling issues. Abundance-size distributions showed a curved pattern on a log-log scale with a flattened lower tail and an upper tail that appeared Paretian. Ponds represented $95 \%$ of the total water body number. Total number of water bodies decreased with coarser spatial resolutions. However, clusters of small water bodies were merged into single larger water bodies leading to local overestimation of water surface area. To assess the uncertainty of coarse-scale products, both surface water fraction and the water body size distribution should therefore be considered. Using Landsat surface albedo to estimate SWC across different terrain types including polygonal terrain and drained thermokarst basins proved to be a robust approach. However, the albedo-SWC relationship is site specific and needs to be tested in other Arctic regions. These findings present a baseline to better represent small water bodies of Arctic wet tundra environments in regional as well as global ecosystem and climate models.
\end{abstract}


Keywords: remote sensing; scaling; surface hydrology; permafrost; ponds; albedo; subpixel mapping

\section{Introduction}

Wetlands cover about $8 \%\left(396,000 \mathrm{~km}^{2}\right)$ of the non-glaciated Arctic tundra surface [1]. Low relief and the underlying permafrost impede drainage in these areas, so that the water table is slightly above or below the ground surface. Wetlands are therefore characterized by poorly drained, highly saturated soils as well as abundant ponds and lakes, which support unusually productive habitats in an otherwise dry and barren environment. Organic wetland soils store large amounts of carbon [2] and both tundra surfaces and water bodies are a main source of carbon dioxide and methane to the atmosphere [3]. A changing Arctic climate may alter the spatial extent of wetlands as well as the number and occurrence of water bodies affecting high-latitude carbon, water and energy fluxes [4,5]. Thawing of permafrost may either increase the number of ponds and lakes when thermokarst depressions fill with water [6,7], or decrease their number when permafrost thaw results in drainage of water bodies [8-10]. Ponds, i.e., water bodies with a surface area smaller than $10^{4} \mathrm{~m}^{2}$, are by far the dominant water bodies in Arctic wetlands [11-13]. They have been recognized as hotspots of biological activity [10], carbon dioxide [14,15] and methane emissions [7,14]. Abnizova et al. [15] found that omission of Siberian tundra ponds would mean an underestimation of landscape carbon dioxide emissions of $35 \%$ to $62 \%$. However, the ponds' impact on regional and global carbon emissions, both current and future, remains difficult to quantify since little information is available regarding their number and occurrence in the Arctic. High-resolution assessments of water bodies including ponds have been conducted only in northeast Siberia [12,13], and in the western Canadian Arctic [11]. Global land cover data sets are limited in spatial detail due to their low resolution. The global lakes and wetlands database (GLWD), for example, only includes lakes larger than $10^{5} \mathrm{~m}^{2}$ [16]. Moreover, both global and regional land cover data sets can be highly inconsistent [17-19], especially in the northern taiga-tundra zone where land cover heterogeneity is high [20]. Muster et al. [13] showed that Landsat data with a resolution of $30 \mathrm{~m}$ cannot resolve ponds and results in an underestimation of water surface area in polygonal tundra by a factor of 1.5 . Scaling procedures are needed to link high-resolution assessments of pond distribution with spatial resolutions of $4 \mathrm{~m}$ or better to the medium- (tens of meter spatial resolution) and low-resolution (hundreds to kilometers spatial resolution) forcing or boundary land cover data sets used in ecosystem and climate models in order to determine the role of Arctic ponds for the regional and global water, energy and carbon balances. Studies have validated circumpolar [21,22] and regional [23-25] subpixel information of Arctic surface waters up to resolutions of $30 \mathrm{~m}$. Locally calibrated studies, on the other hand, provide great detail but are limited to small areas [26]. Medium-scale Landsat data with a resolution of $30 \mathrm{~m}$ provides a link between such high- and low-resolution remote sensing data. Surface albedo has been shown to be proportional to the subpixel surface water fraction. Studies have used this relationship for example to estimate the subpixel fraction of wet bare soil [27,28] and melt ponds on sea ice [29,30]. We use Landsat 
surface albedo to estimate the subpixel fraction of open water cover since albedo is a critical physical parameter affecting the Earth's climate and is a standardized parameter implemented in climate models.

This study inventories ponds and lakes in three Arctic tundra wetlands in the Canadian High Arctic, on the Alaska Coastal Plain, and in the Lena Delta in Siberia. High-resolution remote sensing data with resolutions of $4 \mathrm{~m}$ or better are used to assess (i) the size distribution of water bodies; (ii) the loss of information on water body number and water body surface area with decreasing spatial resolution; and (iii) the potential of medium-scale Landsat surface albedo to show the subpixel fraction of open water cover (SWC).

\section{Study Areas}

Study areas are Polar Bear Pass on Bathurst Island in the Canadian High Arctic, Samoylov Island in the Lena Delta in Siberia, Russia, and the Barrow peninsula on the Alaska coastal plain (Figure 1).

The study area on Samoylov Island (SAM) is located in the Lena River Delta, $120 \mathrm{~km}$ south of the Arctic Ocean $\left(72^{\circ} 22^{\prime} \mathrm{N}, 126^{\circ} 30^{\prime} \mathrm{E}\right.$ ) (Figure $1(\mathrm{~b})$ ). SAM is the smallest of the three study areas with 1.76 $\mathrm{km}^{2}$ (Table 1). It is characterized by thermokarst lakes surrounded by low-centered ice-wedge polygonal tundra. Polygonal tundra is composed of elevated dry polygonal rims interspersed with wet depressed polygonal centers and numerous small polygonal ponds (Figure 1(a)). Few high-centered polygons are typically found along lake margins and on elevated plateaus. Polygonal tundra represents about $30 \%$ of the Lena River Delta's land surface [13].

The wetland area of Polar Bear Pass (PBP) is the second largest wetland in the Canadian High Arctic $\left(75^{\circ} 40^{\prime} \mathrm{N}, 98^{\circ} 30^{\prime} \mathrm{W}\right)$. It is a shallow valley running east-west across south-central Bathurst Island with a surface area of about $94 \mathrm{~km}^{2}$ [31] (Figure 1(c)). The wetland is bordered by hills reaching about $240 \mathrm{~m}$ above sea level. Runoff from the adjoining hillslopes moves both water and matter into the wetland zone [32], creating an unusually productive habitat within a polar desert environment.

The Barrow study area (BAR) is located about $10 \mathrm{~km}$ south of Barrow on the Arctic Coastal Plain of northern Alaska $\left(71^{\circ} 15^{\prime} \mathrm{N}, 156^{\circ} 33^{\prime} \mathrm{W}\right)$ (Figure 1). It is the largest of the three sites with an area of about $354 \mathrm{~km}^{2}$ encompassing polygonal terrain, shallow, oriented thaw lakes, and drained thaw lake basins $[33,34]$.

All three sites are peat-forming lowland wetlands underlain by continuous permafrost. Regional climates are characterized by long, dry, cold winters and short, moist, cool summers, with PBP exhibiting the coldest and driest climate of the study areas (Table 1). The snow-free period for BAR and SAM lasts from mid-June to mid-September, but is much shorter at PBP from mid-July to end of August. Vegetation at all three sites can be characterized as predominantly wet tundra with abundant sedges, grasses, mosses and dwarf-shrubs less than $40 \mathrm{~cm}$ in height. According to the Circumpolar Arctic Vegetation Map (CAVM) SAM and BAR are situated within wetland complexes identified as sedge, moss dwarf-shrub wetland and sedge/grass moss wetland, respectively [1]. The PBP wetland area does not appear on the CAVM as it is smaller than the minimum CAVM mapping unit of $196 \mathrm{~km}^{2}$. However, sedge/grass, moss wetlands can be found on Bathurst Island and throughout the Canadian High Arctic. Moreover, the Northern Land Cover Classification (NLCC) classifies about $70 \%$ of the PBP wetland area as wetland, wet sedge or water [25]. 
Figure 1. Location of study areas in the Arctic. (a) Samoylov Island, Lena Delta, Siberia, Russia; (b) Polar Bear Pass, Bathurst Island, Canada; and (c) Barrow peninsula, Alaska, USA. Red lines mark the study areas. In the Barrow study area, orange lines mark selected polygonal terrain, green line marks a drained, vegetated thermokarst basin.
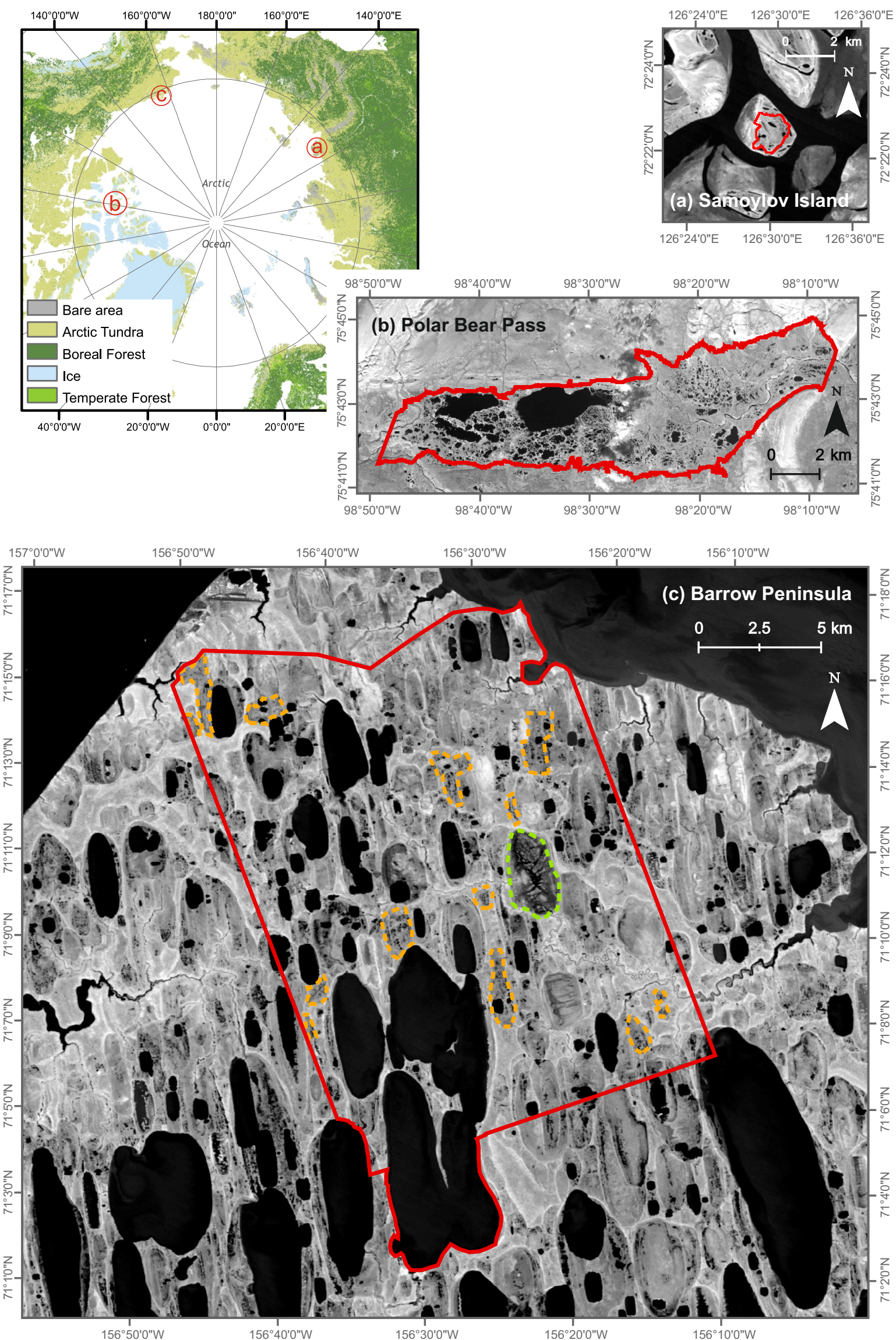
Table 1. Site characteristics of the study areas Polar Bear Pass (PBP), Samoylov Island (SAM), and Barrow peninsula (BAR).

\begin{tabular}{|c|c|c|c|}
\hline & PBP & SAM & BAR \\
\hline Location & $75^{\circ} 40^{\prime} \mathrm{N}, 98^{\circ} 30^{\prime} \mathrm{W}$ & $72^{\circ} 22^{\prime} \mathrm{N}, 126^{\circ} 30^{\prime} \mathrm{E}$ & $71^{\circ} 18^{\prime} \mathrm{N}, 156^{\circ} 33^{\prime} \mathrm{W}$ \\
\hline Study area $\left[\mathrm{km}^{2}\right]$ & 68.6 & 17.6 & 353.6 \\
\hline Permafrost depth [m] & 100 to $500 \mathrm{~m}^{a}$ & 500 to $600 \mathrm{~m}^{e}$ & $\geq 300 \mathrm{~m}^{g}$ \\
\hline Active layer depth [m] & 0.3 to $1 \mathrm{~m}^{b}$ & 0.4 to $0.9 \mathrm{~m}^{f}$ & 0.3 to $0.9 \mathrm{~m}^{h}$ \\
\hline \multicolumn{4}{|l|}{ Climate characteristics } \\
\hline Climate regime & polar desert ${ }^{c}$ & arctic-continental & cold maritime \\
\hline Station & Resolute Bay & Samoylov Island & Barrow \\
\hline Years & $1971-2000$ & 1961-1999 & 1977-2009 \\
\hline Mean annual air temperature & $-16.4^{\circ} \mathrm{C}$ & $-13.6^{\circ} \mathrm{C}^{f}$ & $-12^{\circ} \mathrm{C}^{i}$ \\
\hline Mean July air temperature & $4.3^{\circ} \mathrm{C}^{b}$ & $10.1^{\circ} \mathrm{C}^{f}$ & $3.3^{\circ} \mathrm{C}^{i}$ \\
\hline Mean summer precipitation & $94 \mathrm{~mm}^{d}$ & $125 \mathrm{~mm}^{f}$ & $72 \mathrm{~mm}^{i}$ \\
\hline \multirow[t]{4}{*}{ References } & ${ }^{a}$ Smith and Burgess [35] & ${ }^{e}$ Grigoriev [36] & ${ }^{g}$ Brown and Johnson [37] \\
\hline & ${ }^{b}$ Abnizova et al. [38] & ${ }^{f}$ Boike et al. [39] & ${ }^{h}$ Hinkel and Nelson [40] \\
\hline & ${ }^{c}$ Young and Labine [41] & & ${ }^{i}$ Liljedahl et al. $[42]$ \\
\hline & ${ }^{d}$ Field measurements $2008 \& 2009$ & & \\
\hline
\end{tabular}

Table 2. Sensor type, resolution, water detection thresholds, and acquisition dates of remote sensing data for the study areas Polar Bear Pass (PBP), Samoylov Island (SAM) and Barrow peninsula (BAR).

\begin{tabular}{|c|c|c|c|c|c|}
\hline Site & Satellite Sensor & Resolution & $\begin{array}{l}\text { Water } \\
\text { Detection } \\
\text { Band }\end{array}$ & $\begin{array}{c}\text { Water Detection Threshold } \\
\text { reflectance }[\rho] \\
\text { digital number }[\mathrm{DN}] \\
\text { backscattering coefficient }\left[\sigma^{\circ} \mathrm{db}\right]\end{array}$ & $\begin{array}{l}\text { Acquisition } \\
\text { Date }\end{array}$ \\
\hline \multirow[t]{2}{*}{ PBP } & TerraSAR-X & 2 & $\begin{array}{l}\text { HH polar- } \\
\text { ization }\end{array}$ & $>-21.55 \sigma^{\circ} \mathrm{db}$ & $\begin{array}{l}13 \text { August } \\
2009\end{array}$ \\
\hline & Landsat-5 TM & 30 & NIR band & 0 to $0.03 \rho$ & $\begin{array}{l}28 \text { August } \\
2009\end{array}$ \\
\hline \multirow[t]{2}{*}{ SAM } & VNIR aerial photography & 0.3 & NIR band & 0 to $5438 \mathrm{DN}$ & $\begin{array}{l}1, \quad 9 \text { and } \\
15 \text { August } \\
2008\end{array}$ \\
\hline & Landsat-5 TM & 30 & NIR band & 0 to $0.03 \rho$ & $\begin{array}{ll}25 & \text { July } \\
2007 & \end{array}$ \\
\hline \multirow[t]{2}{*}{ BAR } & KOMPSAT-2 & 4 & NIR band & 46 to $139 \mathrm{DN}$ & $\begin{array}{l}2 \text { August } \\
2009\end{array}$ \\
\hline & Landsat-5 TM & 30 & NIR band & 0.01 to $0.07 \rho$ & $\begin{array}{ll}15 & \text { July } \\
2009 & \end{array}$ \\
\hline
\end{tabular}




\section{Material and Methods}

\subsection{Processing of Remote Sensing Data}

For each study area, high-resolution imagery with spatial resolutions of 0.3 to $4 \mathrm{~m}$ was used to map open water cover. Available high-resolution data included TerraSAR-X imagery for PBP at 2 $\mathrm{m}$ resolution, visible and near-infrared (VNIR) aerial photographs for SAM at $0.3 \mathrm{~m}$ resolution, and multispectral KOMPSAT-2 imagery for BAR at $4 \mathrm{~m}$ resolution (Table 2). Pixel-based classifications of water surfaces were converted from raster to vector files in order to identify contiguous water bodies as discrete objects. GIS analysis of vector data yielded the information about number and size of water bodies. High-resolution water body maps were compared with water body maps based on Landsat-5 TM at $30 \mathrm{~m}$ resolution and the MODIS water mask (MOD44W) at $250 \mathrm{~m}$ resolution [43]. The analysis of water body size distributions included only frost cracks, ponds, and lakes with a minimum surface area of $1 \mathrm{~m}^{2}$ for SAM and $5 \mathrm{~m}^{2}$ for PBP and BAR. All remote sensing data were processed using the image processing software ENVI 4.8 (ITTVIS) and ArcGIS 10 (ESRI).

\subsubsection{VNIR Aerial Imagery of SAM}

Aerial images of Samoylov Island were obtained by mounting two Nikon D200 cameras on a helium-filled blimp. Images were acquired in the visible (VIS) from about 400 to $690 \mathrm{~nm}$ and near-infrared (NIR) ranges above about $830 \mathrm{~nm}$ (together referred to as the VNIR range). The Nikon D200 has a radiometric resolution of 24 bit per pixel. The flights took place at noon on sunny, cloudless days (1, 9 and 15 August 2008). An average flying altitude of $750 \mathrm{~m}$ resulted in a pixel size of about $0.14 \mathrm{~m}$. Sixteen images were used to map the ice-wedge polygonal tundra on Samoylov Island, with an image overlap of about $25 \%$. Land cover classification was carried out individually for each VNIR image. Open water surfaces were extracted using a density slice classification applied to the NIR band. A relative classification accuracy was calculated by comparing the classifications for overlapping areas of adjacent images. In areas where aerial photographs overlapped the land cover classification varied by about $3 \%$ on average [13].

\subsubsection{TerraSAR-X and SPOT-5 Imagery of PBP}

The TerraSAR-X (TSX) image was acquired on 13 August 2009 in Stripmap mode with HH polarization and an incidence angle of $33.29^{\circ}$. The image was obtained as Single Look Slant Range Complex (SSC) and transformed to Single Look Complex (SLC) with the Gamma software [44]. Multilook processing was applied to reduce speckle noise with 3 looks in range and 2 looks in azimuth. Radiometric calibration of the multilook image was done according to Fritz [45] using the following equation:

$$
\sigma^{\circ}=\left(K s * D N^{2}-N E B N\right)
$$

where the digital number, $D N$, i.e., the amplitude of the backscattered signal of each pixel, was transformed into a backscattering coefficient, $\sigma^{\circ}$, corrected for sensor noise, $N E B N$ (Noise Equivalent 
Beta Naught), on a linear scale. This calibration takes into account the calibration constant, $K s$, which is provided in the image data. Correction for variation in local incidence angle with terrain was neglected due to the low gradient of topography in the study area.

The backscattering coefficients were then calculated in decibels by the following formula:

$$
\sigma_{\mathrm{db}}^{\circ}=10 * \log _{10}\left(\sigma^{\circ}\right)
$$

The resulting multi-looked image was geocoded to UTM WGS84 using a look-up table based on a DEM [46] which was generated from Canadian Digital Elevation Data 1:50,000 [47]. The remaining signal-dependent noise SAR speckling was reduced by the application of a 11 by 11 pixel Gamma filter [48].

For the PBP study area, a pixel threshold for water body delineation was fitted according to reference data from high-resolution aerial photography and field mapping for a small area of about $500 \mathrm{~m}^{2}$. Consequently, pixels with brightness values $<-21.55 \sigma_{\mathrm{db}}^{\circ}$ were classified as open water. A majority filter with a kernel size of $7 \times 7$ pixels was applied to reduce spurious pixels in the classification. The PBP wetland zone was defined as all area below elevations of $30 \mathrm{~m}$, and only water bodies that did completely fall within this zone were considered for analyses.

A SPOT-5 image from 25 August 2009 was available for the study area. The image had a resolution of $10 \mathrm{~m}$ in multispectral mode with four bands ranging from 500 to $1,750 \mathrm{~nm}$. The image was used as ancillary information to confirm the TSX-based water classification with the help of the NIR band.

\subsubsection{KOMPSAT-2 Imagery of BAR}

Two acquisitions of KOMPSAT-2 were available on August 2, 2009. KOMPSAT-2 provides imagery with a single panchromatic band between 500 and $900 \mathrm{~nm}$ at $1 \mathrm{~m}$ resolution and four spectral bands between 450 and $900 \mathrm{~nm}$ at $4 \mathrm{~m}$ resolution. Radiometric resolution of the sensor is 10 bit per pixel. Open water surfaces were extracted using a density slicing applied to the NIR band at $4 \mathrm{~m}$ resolution. Cloud shadows were removed manually from the water body classification.

\subsubsection{Landsat-5 Thematic Mapper (TM)}

The Landsat-5 TM images were corrected towards surface reflectance values using Chavez-COST based corrections $[49,50]$ including the Dark Object Subtraction (DOS) and the COSine Transmittance (COST) effects. The image-based DOS compensates for the atmospheric scattering [51]. We subtracted the signal of the atmosphere so that surface reflectances of tundra were in the range of 0.06 to 0.10 in the red and 0.10 to 0.27 in the near-infrared range.

The Landsat calibration tool in ENVI 4.8 (ITTVIS) normalizes the Landsat at-sensor radiance data against the solar irradiance [52] and for yearly variations in the Sun-Earth distance. According to the Chavez-COST method [49], the COSine effect accounts for different solar zenith angles. We did not correct for the cosine-dependant atmospheric transmittance as the COST method handles this variable optionally and does not recommend it for low sun elevation angles. 
The reflectance, $\rho$, is defined as

$$
\rho=\frac{\pi\left(L_{\mathrm{sat}}-L_{\mathrm{path}}\right) d^{2}}{E S U N_{\lambda} \cos \theta_{\mathrm{s}}}
$$

where $L_{\text {sat }}=$ spectral radiance at sensor $\left[\mathrm{Wm}^{-2} \mathrm{sr}^{-1} \mu \mathrm{m}\right], L_{\text {path }}=$ atmospheric path (relative scattering component [51]), $\mathrm{d}=$ Earth-Sun distance [astronomical units], ESUN = mean exoatmospheric solar irradiance $\left.\left[\mathrm{Wm}^{-2} \mu \mathrm{m}\right]\right], \cos \theta_{\mathrm{s}}=$ COSine effect, and $\theta_{\mathrm{s}}=$ Solar zenith angle $\left[^{\circ}\right]$.

Classification of water bodies from Landsat data was done using a density slicing of the NIR band. The pixel threshold value that resulted in the closest agreement between Landsat water body area and high-resolution water body area was chosen.

\subsubsection{MODIS Water Mask}

For the area from $60^{\circ} \mathrm{N}$ to $80^{\circ} \mathrm{N}$ the MODIS water mask (MOD44W) was derived from Terra MODIS data MOD44C 250 m 16-day composites. Data from May to September of three years (2000-2002) was used [43]. Data were classified using regression tree classification, which yields a subpixel estimate of the water component of a pixel. Features were determined to be water bodies if the averaged classification result showed a water content of $50 \%$ or greater. Water pixels were included in the final product when a pixel was identified as water at least $50 \%$ of the time during the observation period between 2000 and 2002 [53].

\subsection{Accuracy Assessment of Water Body Classification}

Robust threshold methods were selected to extract open water surfaces from the high-resolution imagery as well as the Landsat-5 TM data in this study. Water absorbs most of the incoming irradiation in the near-infrared (NIR) and the X-band of the electromagnetic spectrum so that water bodies appear very dark in these spectral bands. Open water can therefore be mapped applying a threshold in a NIR or X-band that divides land and water pixels. The cut-off value is extracted individually for images due to different illumination and acquisition geometry and different sensor spectroradiometry. The NIR threshold method has been shown to produce similar or even better results compared with multispectral classifications [54-56]. Moreover, threshold-slicing in the NIR wavelength region allows to extract water pixels that appear atypical in the visible spectral wavelength range due to sky glint, turbidity, and lake bottom reflectance, which are common at high latitudes due to low sun zenith and abundance of shallow water bodies.

In the case of medium-scale data like Landsat with a resolution of $30 \mathrm{~m}$, high-resolution aerial photography as well as high-resolution satellite imagery is used as "ground truth" to evaluate the accuracy of lake classification [55-57]. In this study, neither image nor field data were available at a sufficient resolution to evaluate the high-resolution water body classifications. However, in the near-infrared as well as in the X-band grey values in the images show a sharp contrast between the water body and the surrounding tundra and classification accuracy is expected to be high (Figure 2). Nevertheless, two types of errors may affect the accuracy of water body classification, i.e., omission errors and commission errors. 
Figure 2. Subsets of study areas show detailed views of water body classifications from (a) TerraSAR-X imagery for Polar Bear Pass (PBP) with a resolution of 2 m; (b) Kompsat2 NIR imagery for Barrow peninsula (BAR) with a resolution of $4 \mathrm{~m}$; and (c) NIR aerial imagery of Samoylov Island (SAM) with a resolution of $0.14 \mathrm{~m}$.

(a) TerraSAR-X $(\mathrm{HH})$ at PBP
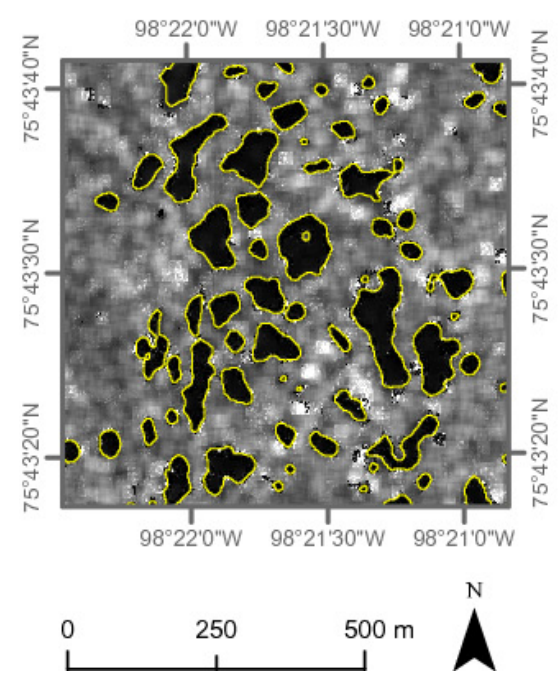

(b) Kompsat-2 (NIR band) at BAR
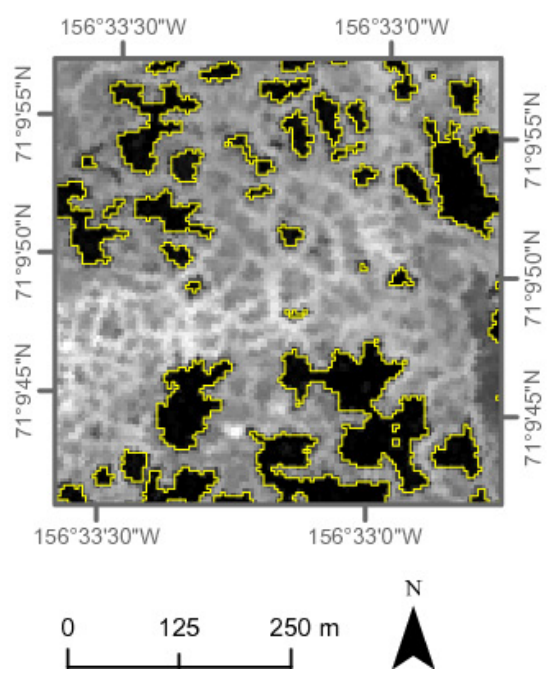

(c) Aerial imagery (NIR band) at SAM
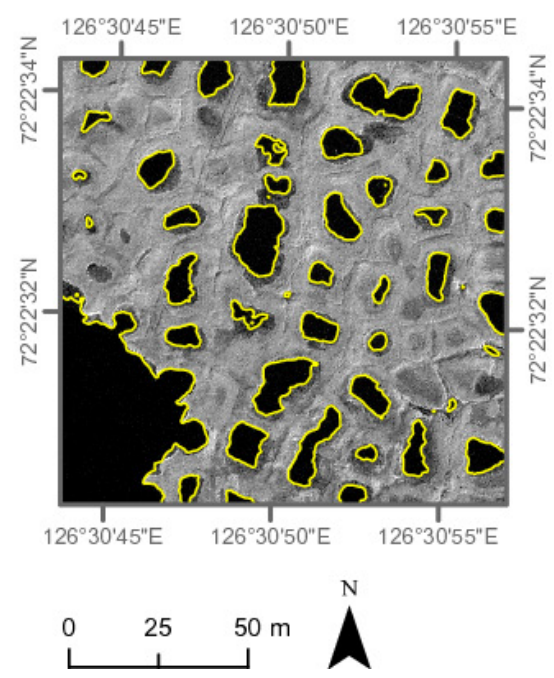

Omission errors are due to low spatial resolution so that smaller water bodies are not mapped. Omission errors can be ruled out for SAM and PBP with image resolutions of 0.18 and $2 \mathrm{~m}$, respectively. Omission errors may occur for BAR with a resolution of $4 \mathrm{~m}$.

Commission errors depend on the spectral resolution of the remote sensing data so that a spectral signal is misinterpreted as water where in reality it may be wet soil. In the near-infrared, commission errors may occur for single pixels where small patches of wet soil or shadows due to microtopography or clouds are misinterpreted as water. Cloud shadows can be ruled out with the help of all four bands (R, G, B, NIR) available for the Kompsat-2 imagery and the aerial imagery.

In the X-band, rough water surfaces due to high wind speeds may be confounded as tundra surfaces as the X-band is very sensitive to surface roughness. However, wind speeds were low during acquisition time of the TSX image and water surfaces were calm. Furthermore, wet snow or wet soil as well as shadows may show the same threshold as open water in the X-band. Based on field observations of PBP, no snow persisted in the study area in mid-August. Wet soil and shadows due to microtopography appear in patch sizes much smaller than the minimum size pond threshold of $5 \mathrm{~m}^{2}$ and were excluded from the classification. A SPOT-5 image (from 25 August 2009) with a resolution of 10m was used to visually check the water body classification from the TSX image and remove any pixels falsely identified as water. All water bodies identified in the SPOT image were also identified in the TerraSAR-X image.

\subsection{Subpixel Analysis of Landsat Surface Albedo}

We investigated the relationship between surface albedo, $\alpha$, calculated from the Landsat surface reflectance, $\rho$, and the subpixel water cover (SWC) within each Landsat pixel. This study and others (e.g., [58-60]) use the broad-band reflectance as the surrogate for the integrated hemispherical albedo. 
Albedo is defined as the fraction of incident radiation that is reflected by a surface. While reflectance is defined as this same fraction for a single incidence angle, albedo, in its strict sense, is the directional integration of reflectance over all sun-view geometries. For sensors with wide-viewing angles like MODIS, AVHRR, SeaWIFS and MERIS, bi-directional distribution function (BRDF) corrections are needed. The Landsat sensor, however, has a viewing angle of only $15^{\circ}$. First BRDF measurements of tundra North of $70^{\circ}$ using a field goniometer show that the anisotropy effect would account for maximal $1 \%$ albedo for the backward looking $\left(-7.5^{\circ}\right)$ viewing geometry and for smaller than $0.5 \%$ albedo for the forward looking geometry $\left(+7.5^{\circ}\right)$ viewing geometry at the outermost pixels of a Landsat acquisition depending on the sun azimuth [61]. Within this study, the regions of investigations comprised only subsets of the Landsat acquisitions with minor anisotropic effects.

Ninety-eight percent of the solar radiation received at the Earth is in the range of about 0.3 to $2.5 \mu \mathrm{m}$, which is covered by Landsat. Broad-band Landsat surface albedo was calculated from Landsat band reflectances from band $2(520-600 \mathrm{~nm}), 4(760-900 \mathrm{~nm})$ and $7(2,080-2,350 \mathrm{~nm})$ according to the formula by Brest and Goward [58] and Duguay and Ledrew [59] for vegetated surfaces:

$$
\alpha=0.526 \rho_{\text {band } 2}+0.362 \rho_{\text {band } 4}+0.112 \rho_{\text {band } 7}
$$

Duguay and Ledrew [59] used this formula for albedo estimation of alpine tundra environments. The formula has since been validated by Liang [60]. Liang [60] conducted radiative transfer simulations under varying atmospheric and surface conditions to show that it is possible to calculate coefficients for narrow- to broadband albedo conversion for a range of different sensors. Liang [60] showed that the linear formula by Duguay and Ledrew [59] fit their data of all cover types well, including soil, vegetation canopy, water, wetland, snow, rock, and other cover types.

The main target of this study were mixed pixels, i.e., pixels with SWC between less than 95\% and more than 5\%. Spectra of Landsat mixed pixels are most often characterized by the reflectance of the vegetative component within the pixel. Therefore, the albedo formula for vegetated surfaces was selected and then applied to all Landsat pixels.

Surface water extent in permafrost terrain is strongly affected by seasonal processes, including inundation after snowmelt, progressing thaw depth, evaporation, and precipitation. Whenever possible, high-resolution images and Landsat data were chosen to be from the same year and season, i.e., late summer (Table 2). For SAM, Landsat data was not available for the same year as the aerial imagery, i.e., 1, 9 and 15 August 2008. Instead, Landsat imagery from 25 July 2007 was used. Water balance on Samoylov Island is usually equilibrated, so that water levels and the corresponding water surface area of ponds and lakes do not change significantly for the years of interest [39].

For subpixel analysis, the VNIR aerial imagery and KOMPSAT-2 imagery were registered onto the Landsat imagery in ERDAS IMAGINE 9.2 with a root mean square error of less than 0.5 and 1.6 pixel, respectively. All water surface types, i.e., ponds, lakes, frost cracks, rivers, and streams were used for the calculation of subpixel open water cover (SWC). Maps of open water surfaces derived from high-resolution imagery were then used to calculate the SWC within each Landsat pixel. Consequent analysis of the relationship between SWC and albedo was done for albedo values with a minimum of five repetitions. 


\section{Results}

\subsection{Abundance and Size Distribution of Water Bodies}

Water bodies at all three sites were dominated in number by ponds, i.e., water bodies with a surface area smaller than $10^{4} \mathrm{~m}^{2}$, but dominated in area by a few large lakes (Figures 3 and 4(a)). The total number of water bodies (area-normalized per $10^{7} \mathrm{~m}^{2}$ ) was about a magnitude higher at SAM than at PBP and BAR (Table 3). The study area at SAM featured only polygonal tundra. Thermokarst lakes contributed less than $1 \%$ to the total water body number and showed maximum surface areas of $4.1 \times 10^{4} \mathrm{~m}^{2}$. The larger study areas of PBP and BAR, however, featured a greater variety of pond and lake sizes. Maximum lake surface area was $5.6 \times 10^{6} \mathrm{~m}^{2}$ for PBP, and $4.7 \times 10^{7} \mathrm{~m}^{2}$ for BAR.

The proportion of ponds to the total water surface area diminished with an increasing number of large lakes in the study areas (Figure 3). BAR showed a total pond surface area of only $4 \%$, followed by PBP with $22 \%$, and SAM with $49 \%$. However, ponds contributed more than $95 \%$ to the total number of water bodies in each study area. Even ponds with a surface area of $10^{3} \mathrm{~m}^{2}$ or less remained a dominant group contributing $60 \%$ to the total number of water bodies at PBP, $87 \%$ at BAR and $99 \%$ at SAM (Figure 3). At BAR, the minimum water body size was $16 \mathrm{~m}^{2}$ and increased in a stepwise pattern of $4 \times 4 \mathrm{~m}$, which reflected the pixel size of the KOMPSAT imagery used for water body delineation.

Figure 3. Cumulative ratio of water body surface area to the total water surface area (dotted lines) and cumulative ratio of number of water bodies per surface area to the total abundance (thick lines) for Polar Bear Pass (PBP), Samoylov Island (SAM) and Barrow peninsula (BAR). Vertical lines indicate the pixel size of Landsat with $30 \times 30 \mathrm{~m}$ and MODIS with $250 \times 250 \mathrm{~m}$.

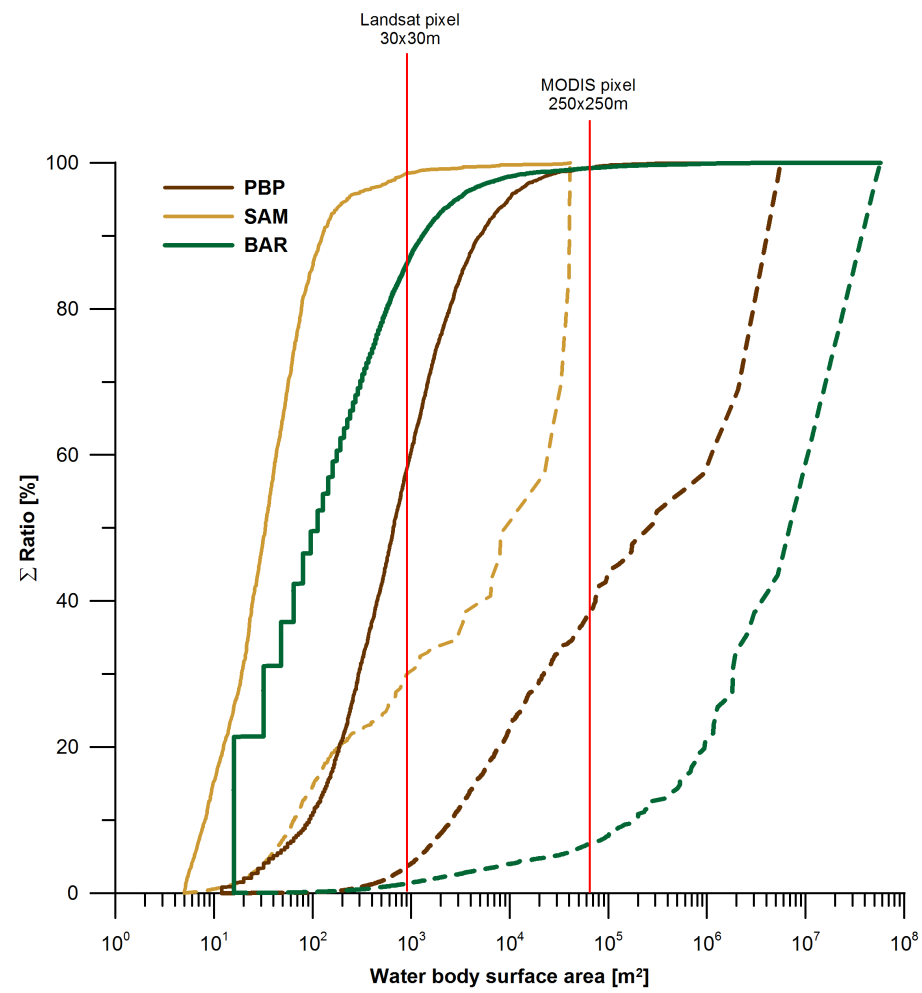


Figure 4. Size distributions of water bodies for Polar Bear Pass (PBP) in red, Samoylov Island (SAM) in black and Barrow peninsula in blue on a double logarithmic scale (base 10). Size distributions are derived from (a) high-resolution imagery with resolutions of $4 \mathrm{~m}$ or better; (b) Landsat-5 TM imagery with a resolution of $30 \mathrm{~m}$; and (c) from the MODIS water mask (MOD44W) with a resolution of $250 \mathrm{~m}$. No water bodies were mapped for SAM from MOD44W.
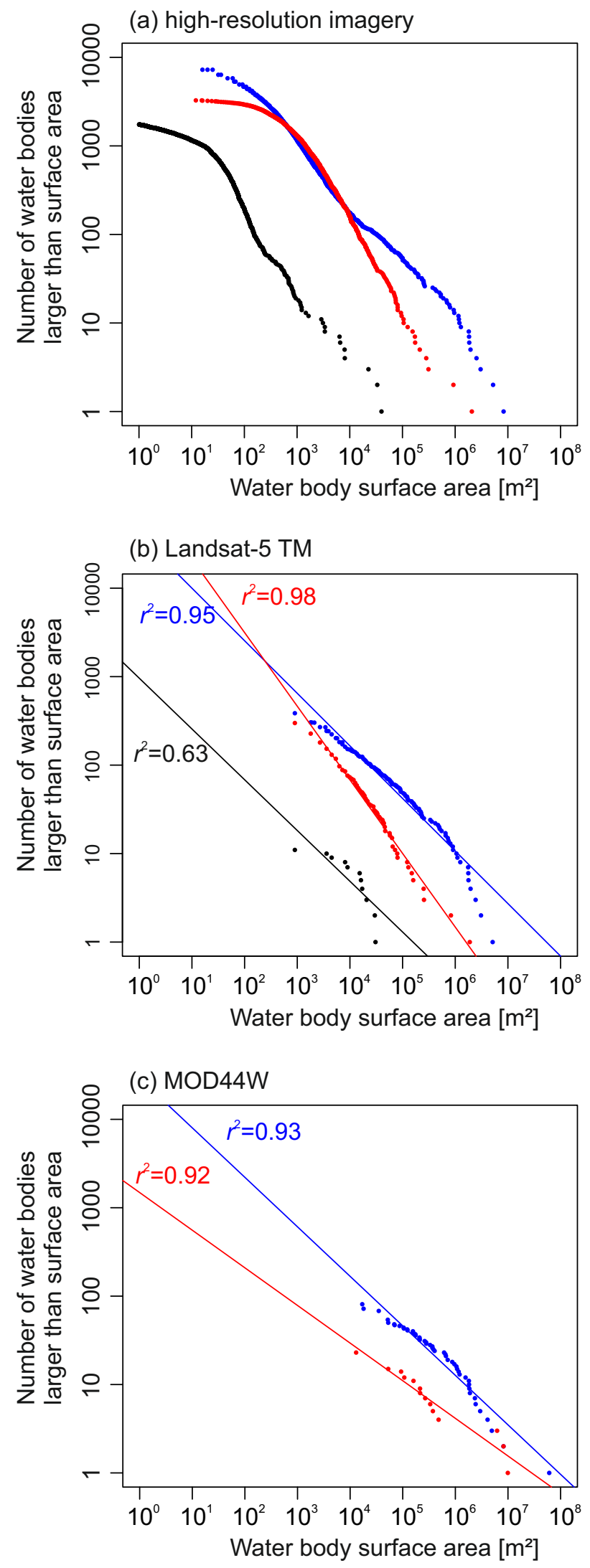
Table 3. Descriptive statistics of water bodies $\geq 5 \mathrm{~m}^{2}$ in the study areas of Polar Bear Pass (PBP), Samoylov Island (SAM) and Barrow peninsula (BAR).

\begin{tabular}{lccc}
\hline & SAM & PBP & BAR \\
\hline Number of water bodies & 1342 & 3293 & 9225 \\
Number of ponds $\left(<0.01 \mathrm{~km}^{2}\right)$ & 1338 & 3133 & 9049 \\
Number of lakes $\left(\geq 0.01 \mathrm{~km}^{2}\right)$ & 4 & 160 & 176 \\
Total water body area $\left[\mathrm{m}^{2}\right]$ & $2.7 * 10^{5}$ & $1.8 * 10^{7}$ & $1.0 * 10^{8}$ \\
Maximum size $\left[\mathrm{m}^{2}\right]$ & $4.1 * 10^{4}$ & $5.6 * 10^{6}$ & $4.7 * 10^{7}$ \\
Minimum size $\left[\mathrm{m}^{2}\right]$ & 5.0 & 12.0 & 16.0 \\
Mean size $\left[\mathrm{m}^{2}\right]$ & 200 & $5.5 * 10^{3}$ & $1.1 * 10^{4}$ \\
Median size $\left[\mathrm{m}^{2}\right]$ & 30 & 700 & 100 \\
Standard deviation $\left[\mathrm{m}^{2}\right]$ & $1.9 * 10^{3}$ & $1.1 * 10^{5}$ & $5.1 * 10^{5}$ \\
Normalized per $10^{7} \mathrm{~m}^{2}$ & & & \\
Total number of water bodies & 76216 & 4804 & 2609 \\
Number of ponds & 75989 & 4571 & 2559 \\
Number of lakes & 227 & 233 & 50 \\
\hline
\end{tabular}

Visually, the upper tail of the high-resolution size distributions fit well a Pareto distribution. The Pareto distribution is a power law probability distribution in the form of $N=x A^{y}$, which appears linear on a log-log plot. Using the Pareto distribution, however, to extrapolate missing data in the lower tail of the distribution would lead to an overestimation of small water bodies. Size distributions of ponds and lakes at all sites appeared linear on a log-log plot in the upper tail of the distribution, i.e., for water bodies larger than about $400 \mathrm{~m}^{2}$ for PBP, $30 \mathrm{~m}^{2}$ for SAM and $100 \mathrm{~m}^{2}$ for BAR (Figure 4). Water bodies smaller than these thresholds, i.e., in the lower tail of the size distribution, showed no substantial increase in lake abundance. Since the smallest and largest lakes differed in size for the study areas, distribution curves were located at different points along the abscissa.

Landsat- and MODIS-based size distributions at PBP and BAR (Figure 4(b,c)) do not show the flattened lower tail. Linear regressions on the log-abundance log-size plots show high $r^{2}$ values of 0.98 for PBP and 0.95 for BAR (Figure 4(b)) and could therefore be mistaken for power-law distributed data. Landsat-based size distribution of SAM, however, significantly deviates from linearity with a $r^{2}$ value of only 0.63 .

\subsection{Effect of Scale on Water Body Mapping}

Water body surface area and water body number derived from the high-resolution imagery were set to $100 \%$ for comparative purposes with water body mapping based on Landsat-5 TM and the MODIS water mask (MOD44W) (Figure 5). Water surface area mapped with Landsat amounted to 64\% of the total water surface area at PBP, 44\% at SAM, and 95\% at BAR (Figure 5). For PBP and BAR, MOD44W showed a close agreement with the actual water surface area (Figure 5). The spatial distribution, however, of ponds and lakes changed for both Landsat and MOD44W, which can be seen in Figure 6. At PBP, 
clusters of ponds and small lakes converged into larger continuous water bodies. This effect was most pronounced for MOD44W but is also present for Landsat based mapping. The convergence of small water bodies in close proximity can be expected in coarse resolution datasets from Landsat and/or MODIS as compared with field data or very fine resolution remote sensing because the pixel size does not permit distinguishing sub-pixel lakes as individual entities.

Figure 5. Water body surface area and water body number mapped at different resolutions for Polar Bear Pass (PBP), Samoylov Island (SAM) and Barrow peninsula (BAR). Bars show the ratio of water surface area to the total water body surface area mapped at the highest resolution. Lines show the ratio of water body number to the total number mapped at the highest resolution. Water bodies were mapped at PBP from TSX imagery with $2 \mathrm{~m}$, at SAM from VNIR aerial imagery with $0.3 \mathrm{~m}$, and at BAR from KOMPSAT-2 imagery with $4 \mathrm{~m}$ resolution. $30 \mathrm{~m}$ resolution water body maps were derived for all sites from Landsat-5 TM imagery. Water bodies at $250 \mathrm{~m}$ were extracted from the MODIS water mask (MOD44W) [43].
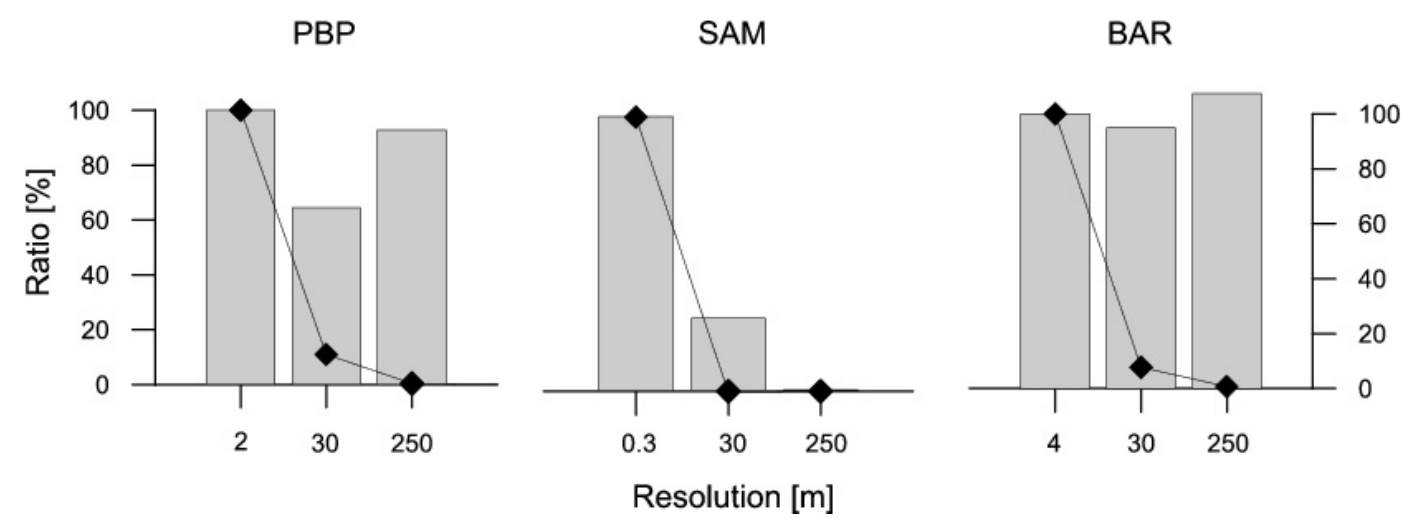

Underestimation of the number of water bodies was even stronger than underestimation of the water surface area. At SAM, only $0.8 \%$ of the total water body number could be detected with Landsat, $8 \%$ at BAR, and $13 \%$ at PBP. Water body number further decreased in MOD44W with a resolution of $250 \mathrm{~m}[43]$ to less than $1 \%$ at PBP and BAR, and no water bodies were detected at SAM.

\subsection{Subpixel Analysis of Landsat Albedo}

To characterize Landsat surface albedo in the study areas, pixels were grouped into three categories: water pixels (SWC of $95 \%$ and higher), land pixels (SWC of 5\% and lower) and mixed pixels (SWC between $95 \%$ and $5 \%$ ).

Mean water albedo and mean land albedo were similar across study sites (Figure 7). However, land albedo showed a much wider range at PBP and BAR than at SAM. The mean albedo values of water pixels ranged from 0.05 at SAM and BAR to 0.06 at PBP (Figure 7(a)). Outliers of water albedo were predominantly associated with water pixels along pond and lake margins or with water bodies that were close to the Landsat resolution of $30 \mathrm{~m}$ in width and/or length. The mean albedo values of land pixels ranged from 0.12 at SAM to 0.13 at PBP and BAR (Figure 7(b)) which were associated with wet tundra. Land albedo reached maxima of 0.25 for PBP, 0.15 for SAM, and 0.17 for BAR. At PBP, albedo values larger than 0.17 were associated with alluvial gravel deposits of the flood plain and sandy-gravel ridges 
with little to no vegetation within the wetland. At SAM, albedo values larger than 0.13 represented Landsat pixels dominated by dry tundra. BAR land pixels showed lowest albedo values of less than 0.08 , which were associated with drained thermokarst basins.

Figure 6. Water bodies (blue areas) in Polar Bear Pass (PBP) mapped at different resolutions from (a) TerraSAR-X imagery (HH polarization) with $2 \mathrm{~m}$ resolution; (b) Landsat-5 TM imagery with $30 \mathrm{~m}$ resolution; and (c) MODIS water mask (MOD44W) with $250 \mathrm{~m}$ resolution [43]. Red line marks the study area.
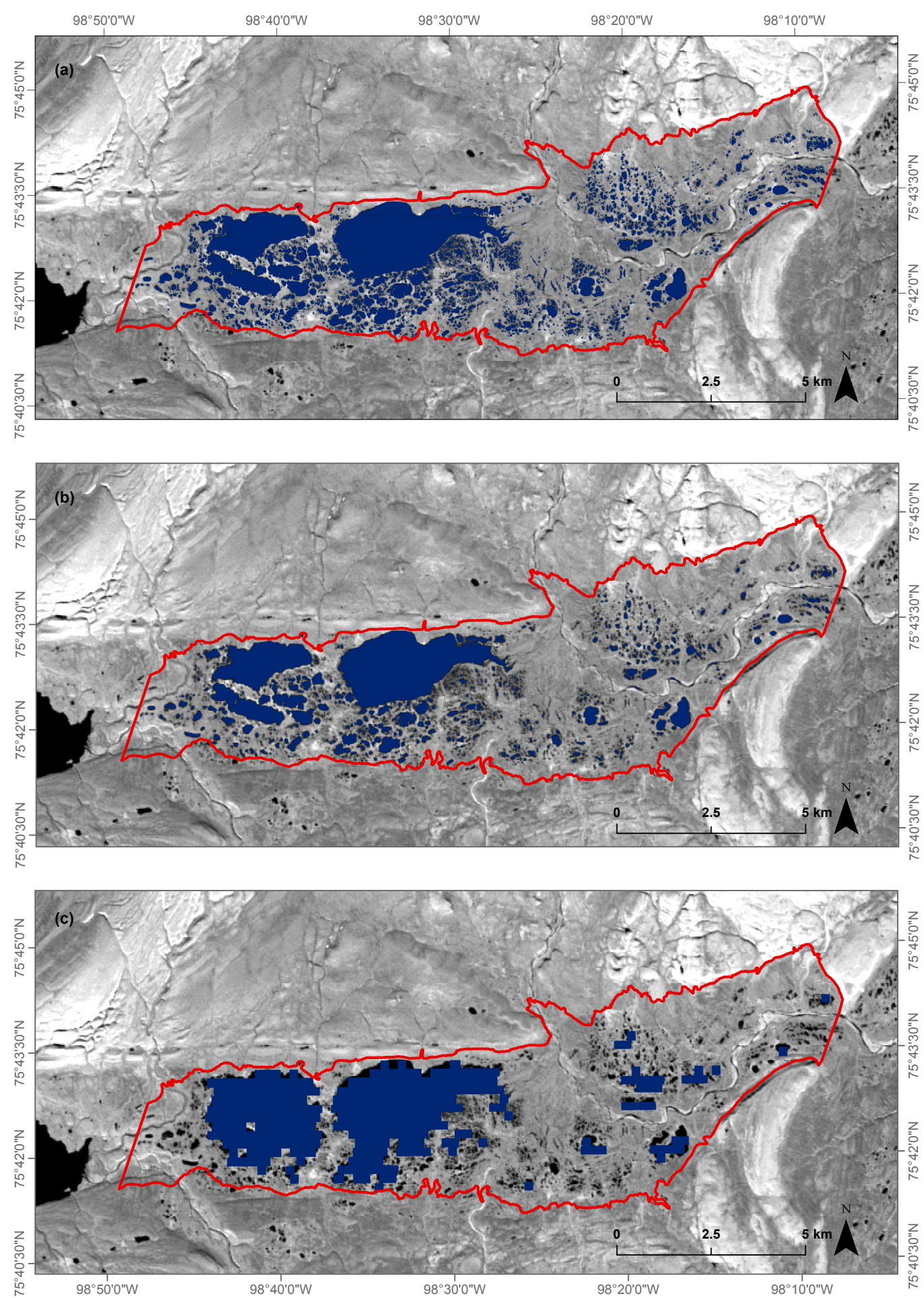
Figure 7. Range of Landsat albedo values for Polar Bear Pass (PBP), Samoylov Island (SAM) and Barrow peninsula (BAR) for (a) water pixels; (b) land pixels; and (c) mixed pixels. Boxplots show minimum, lower quartile, median, upper quartile, maximum, and outliers.
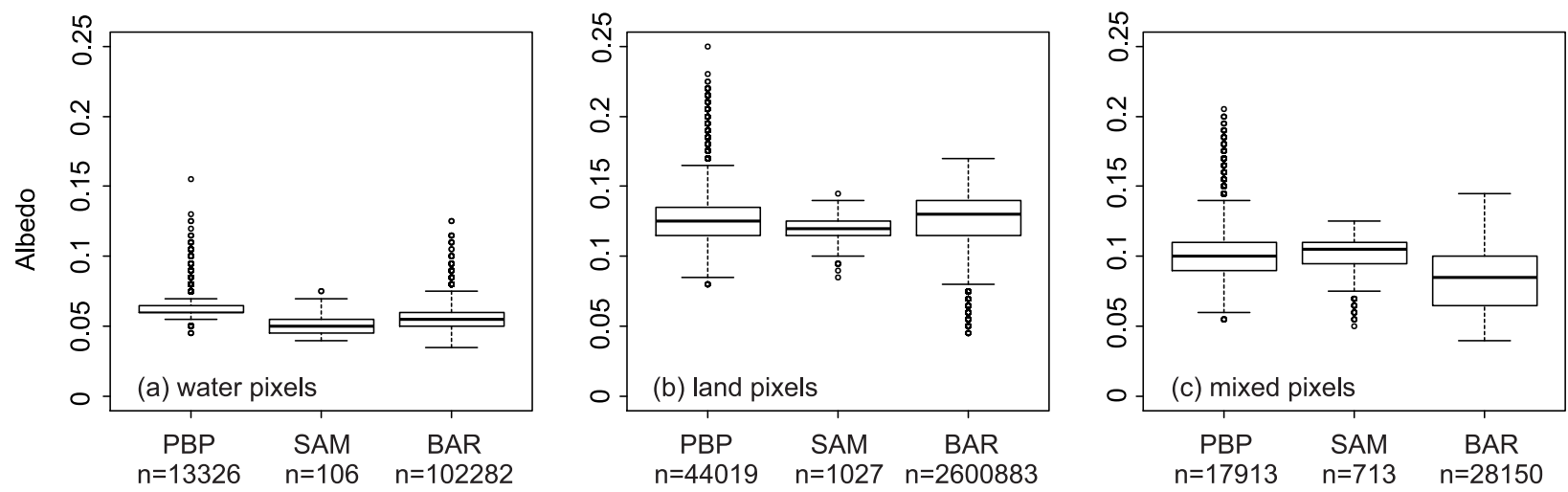

Figure 8. Mean subpixel proportion of open water cover per Landsat surface albedo. Corresponding shaded areas show the 20th and the 80th percentile of the data. Panel (a) shows the total study areas of Polar Bear Pass (PBP) (red line), Samoylov Island (SAM) (black line), and Barrow peninsula (BAR) (blue line); Panel (b) shows the mean subpixel proportion of water cover per Landsat albedo for the total BAR study area (blue line), for polygonal terrain (orange line) and a vegetated, drained thermokarst basin (green line), only.
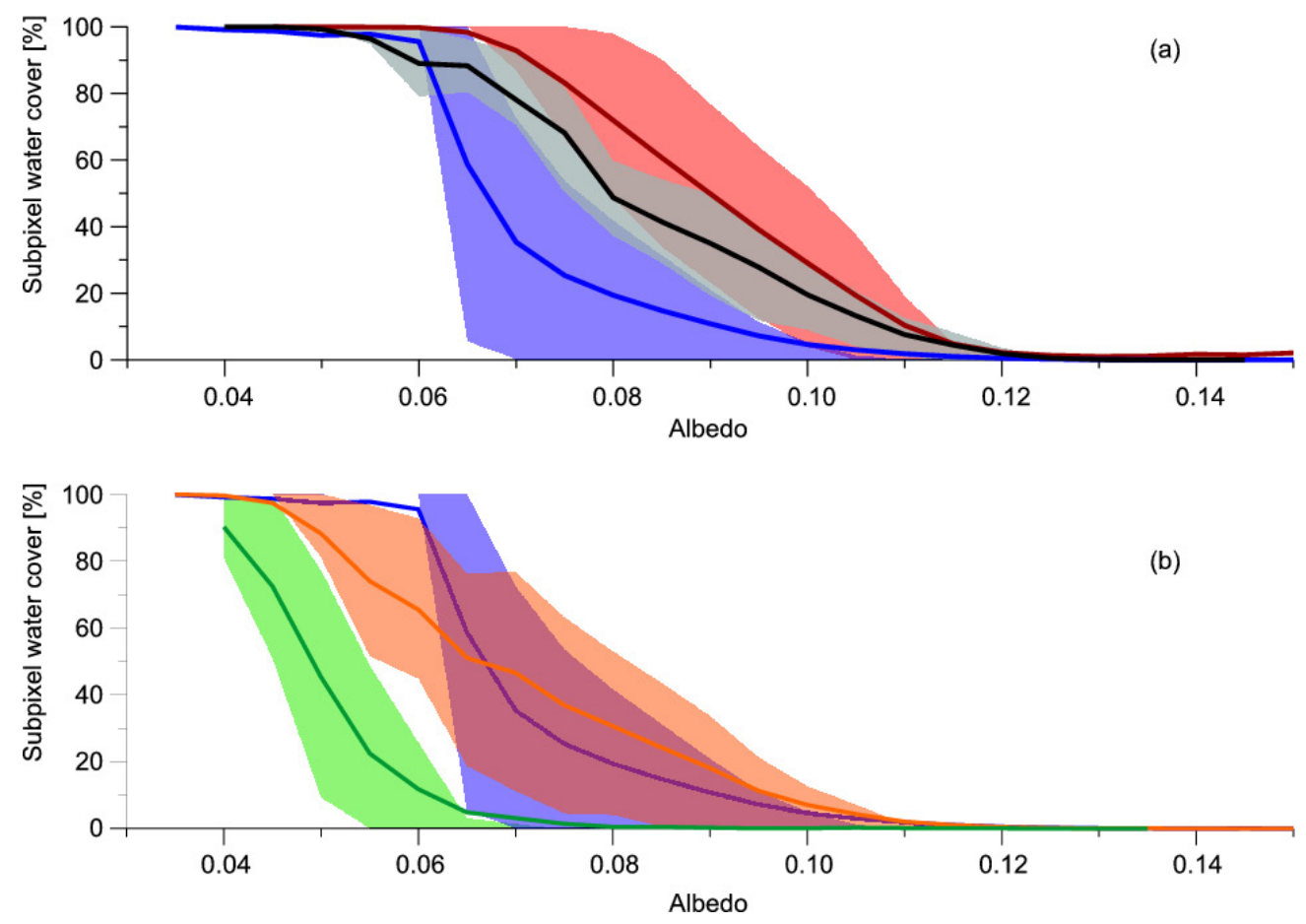

For all sites, SWC decreased with increasing albedo (Figure 8(a)). The albedo-SWC relationship appeared strongly linear for mixed pixels at PBP and SAM, but less so for BAR. Between albedo 0.06 and 0.08 at SAM, SWC was about $10 \%$ higher than the linear relation predicts. BAR exhibited lowest 
albedo for mixed pixels, and albedo showed about $20 \%$ to $50 \%$ less SWC than at PBP and SAM. The albedo-SWC relationship of PBP and SAM differed between $10 \%$ and $20 \%$ SWC. For all sites, the mean standard deviation (SD) of SWC was equal to or less than $1 \%$ for water and land pixels. SWC of mixed pixels showed an SD of $27 \%$ for BAR, followed by PBP with $26 \%$, and SAM with $21 \%$. At all sites, SD decreases towards the upper and lower end of the function.

The BAR albedo-SWC function shown in Figure 8(a) includes the whole study area. BAR, however, was composed of many different terrain types like polygonal terrain and depressed thermokarst basins for which separate albedo-SWC functions were calculated (Figure 8(b)). Although SD did not improve significantly with $24 \%$ for polygonal terrain and $27 \%$ for the thermokarst basin, the relationship between SWC and albedo appeared strongly linear for each landscape subtypes compared with the albedo-SWC relationship for the whole study area. The range of albedo in the thermokarst basin was significantly lower than for the other areas. Albedo of polygonal terrain of BAR was within the albedo range of PBP and SAM but SWC was lower.

\section{Discussion}

\subsection{Size Distribution of Ponds and Lakes Across Scales}

Circumpolar and global water body mapping is limited by the low spatial resolution of large-scale imagery. Previous studies therefore attempted to estimate small water bodies that could not be mapped. The linear behaviour of the size distributions for larger water bodies has been used to estimate smaller water bodies using the Pareto distribution $[12,16,62,63]$. In the present study, however, application of the Pareto distribution would lead to an overestimation of the number of small water bodies. In all three wetlands, resolutions of 0.3 to $4 \mathrm{~m}$ make water body mapping nearly complete. The flattened lower tail is therefore very likely an inherent property of the size distributions. Similar flattened tails have been observed by Seekell and Pace [64] and McDonal et al. [65] for study areas in the United States. In a recent study, Seekell et al. [66] compare lake data from a mountainous and a flat region and attribute difference in lake size distributions due to the differences in topography. Seekell et al. [66] suggest that the power-law relationship, e.g., in form of a Pareto distribution, is confined to flat regions. This does not conform to results from this study where size distributions do not appear Paretian although all study sites are located in flat regions. However, their lake sizes from the flat region are derived from Landsat with a minimum lake size threshold of $10^{4} \mathrm{~m}$ and omit smaller water bodies that are found in the study area [67]. This study indicates that Landsat- and MODIS-based water body size distributions can be mistaken to follow a power law function whereas higher resolution water body classifications reveal that this is not the case. Based on our results we argue that the existence of a flattened lower tail depends on the image resolution and that conclusions about the effect of geomorphic constraints may need further investigation.

The flattened lower tail is well pronounced for SAM and PBP where water bodies were mapped at $0.14 \mathrm{~m}$ and $2 \mathrm{~m}$. At BAR where water bodies were mapped at a resolution of $4 \mathrm{~m}$, the flattened lower tail is not as well pronounced, indicating missing water bodies. In polygonal tundra at SAM, ponds have a mean area of about $10 \mathrm{~m}^{2}$. Although ice-wedge polygonal tundra is a common feature 
on the Alaska coastal plain [68], polygonal ponds as small as at SAM could not be mapped at BAR due to the pixel size of the KOMPSAT imagery with $16 \mathrm{~m}^{2}$. Thus, the total number of water bodies is likely to be even larger for BAR. An increase in water body area by $10 \%$ would mean that over 600,000 water bodies smaller than $16 \mathrm{~m}^{2}$ were not mapped. But this number would by far exceed the size distribution of small water bodies at BAR even if we would assume a Pareto-based distribution. Other distributions, like the log-normal distribution, also appear linear in the upper part in a log-log plot. But they estimate water body abundances to be orders of magnitude smaller than abundances predicted from the Pareto distribution [64]. Finding the right model to calculate the size distribution of water bodies, therefore, relies on the completeness of the water body count. Our findings support the conclusions of Seekell and Pace [64] that there exists a need for a more complex approach to model water body size distributions that goes beyond the extrapolation via a Pareto distribution. Size distributions could be approximated using a two part scheme, finding separate functions for the upper and lower tail of the distribution. Seekell et al. [66] propose an extended equation of the power-law relationship within a fractal geometry framework to account for the deviation from linearity in the upper tail of the distribution.

Our study shows the loss of small water bodies when mapping water with Landsat data and in the case of SAM also with the MODIS water mask (MOD44W). It is not surprising that water bodies with surface areas below the image resolution should be omitted in a classification process that does not use a subpixel mapping approach. The overestimation of water surface in MOD44W at PBP and BAR, on the other hand, may therefore seem counterintuitive. This effect is the result of the spatial distribution of water bodies in the landscape. Clusters of small water bodies may dominate the pixel spectrum, which is in turn interpreted as pure water. Many small water bodies are consequently lumped into a single larger water body. This effect has also been pointed out by Lehner and Döll [16] and is amplified by the classification method. In the case of MOD44W, water pixels were identified if the averaged classification result showed a water content of $50 \%$ or greater [43]. The total water surface area may then be similar for both high- and low-resolution mapping, but the water body size distributions differ significantly.

MOD44W is a static product that shows average surface water conditions for the time period from May to September of three years 2000 to 2002. Pixels were classified as water when a pixel was identified as water at least $50 \%$ of the time. This approach smoothens out short-term transitions in water bodies due to flooding or drought. The MOD44W therefore represents average conditions in our study areas. All high-resolution data sets as well as Landsat imagery date from mid-July or later so that water body classifications represent mid-summer conditions and are not affected by tundra flooding due to snow melt. Our water body classifications, however, do represent the water surface state at a specific date and not an average condition of the water surface area. Surface area of wetland ponds at PBP was directly measured in relatively wet summers of 2008 and 2009 and varied $\pm 10 \%$ during mid-summer and in between years due to differences in precipitation and evaporation [38]. Similar mid-summer fluctuations were found by Bowling et al. [69] on the Alaska Arctic coastal plain. An increased water body surface area would decrease the ratio of MOD44W water surface area relative to our high-resolution classification and vice versa. MOD44W does not show any water bodies for SAM. In this case, interannual variability of the water surface area is not a likely cause. The diameters of the largest lakes on SAM do not exceed $125 \mathrm{~m}$. MODIS pixels of $250 \times 250 \mathrm{~m}$ therefore do not show a subpixel water content larger than $50 \%$ and were not classified as water in MOD44W. 


\subsection{Albedo as an Estimator of Subpixel Water Cover}

The correlation between albedo and SWC is linear only for rather homogeneous landscape types, i.e., polygonal terrain of SAM and BAR, drained vegetated thermokarst basins at BAR, and wet tundra at PBP. Open water is the darkest endmember within a Landsat mixed pixel and therefore strongly determines the albedo. However, other dark land surface endmembers like water with immersed vegetation or wet soil also contribute to a low albedo even if the extent of open water within the mixed pixel is small. Conversely, if land surface endmembers have a rather high albedo, a larger proportion of open water is needed within the pixel to result in a low albedo. This argumentation explains both the variation of the SWC-albedo relationship between sites as well as within a site. Different endmember combinations can render the same albedo depending on which endmembers are present, their exact appearance and extent within a mixed pixel. A higher number of endmembers increases the possible number of endmember combinations for the same albedo, which attenuates the albedo-SWC correlation. The number of land surface endmembers present in a study area may thus be one reason for the wider range of the SWC-albedo relationship at PBP and BAR than at SAM. SAM only comprises polygonal tundra with a limited range of surface types, whereas the larger study areas at PBP and BAR show a greater variety of surface types.

Furthermore, the same endmember varies within sites, which is most apparent for open water. Local variation of open water albedo can be due to several factors, including water turbidity, reflection from lake and pond bottom [70], and roughness of the water surface [71]. The solar elevation angle (SEA), i.e., the incidence of the direct radiation, however, exerts the strongest influence [72,73]. Low SEAs lead to larger albedos $[60,70,74]$, which possibly explains the larger open water albedo for PBP. SEA is lowest at PBP with $23.5^{\circ}$, whereas SEA is $37.5^{\circ}$ for SAM and $40.3^{\circ}$ for BAR. Albedo values larger than 0.07 for open water at PBP and BAR represent Landsat pixels that are situated along the margins of water bodies or rivers and streams. Such border pixels are prone to misclassification due to the overlay error between the high-resolution water masks and the Landsat imagery. Border pixels may consequently have been falsely identified as pure water pixels whereas in fact they represent pure land or mixed pixels. For land pixels, the range of albedo is much greater. Compared with open water, land pixels contain several surface types, which are characterized by different vegetation types, surface wetness, and microtopography. Estimated Landsat albedo of Samoylov land surface ranges from 0.09 to 0.14 whereas pyranometer measurements show 0.14 for wet and 0.2 for dry tundra [75]. Differences between albedo estimates from satellite sensors and field measurements are mainly due to two factors. First, the directional reflectance function especially at low SEA influences the directional measurements of satellite sensors much more than the hemispherical measurements of pyranometers [76]. Second, satellite sensors provide clear-sky measurements only, whereas continuous pyranometer measurements include cloudy and diffuse illumination conditions.

The albedo-SWC function is also affected by the quality of the underlying water body map. At SAM, the resolution of $0.3 \mathrm{~m}$ renders the most accurate SWC per Landsat albedo of all three sites, which is another explanation for the lower variation in the albedo-SWC relationship than at PBP and BAR. Resolutions of $2 \mathrm{~m}$ at PBP and $4 \mathrm{~m}$ at BAR already represent averages of very fine-scale land cover pattern and cannot account for very small patches of water, e.g., water with immersed vegetation, 
frost cracks, or water patches within wet tundra. Albedo of land pixels at PBP and BAR, therefore, is probably affected by dark soil and water patches that we could not account for with the available remote sensing imagery.

Seasonal variations in water surfaces are another factor to consider regarding the variation of the SWC-albedo relationship. The SAM high-resolution water body map dates from summer 2008 whereas the Landsat image is from summer 2007. Although field observations confirm the overall consistency of water bodies for these years, shallow waters can be subject to high fluctuations in water levels. We therefore speculate that open water surfaces along banks mapped in 2008 actually appeared as water with emergent vegetation in 2007, which would explain the elevated SWC between albedo values of 0.06 to 0.08 at SAM that are associated with border pixels along the banks of ponds and lakes. At both PBP and BAR, the high-resolution water body maps are from the same year as the Landsat data but date two weeks earlier. At PBP in August 2009, however, water levels were relatively stable even in ponds with dynamic water levels [38] so that seasonal differences in water cover can be ruled out. Similarly, no extreme rain event or drying of the surface was observed at BAR in summer 2009 from available precipitation records (NCDC web archive at http://www.ncdc.noaa.gov/crn/, StationID 1007).

\subsection{Implementation of an Albedo-SWC Function}

This paper proposes the use of Landsat surface albedo to estimate SWC. The albedo-SWC function of mixed pixels appeared linear for all sites, which is why similar results can be expected in other Arctic tundra environments. However, our separate analyses of polygonal terrain and a vegetated, drained thaw lake basin at BAR show that albedo-SWC functions are site-specific and should be derived separately for different regions and surface types.

Our approach distinguishes two endmembers only, i.e., land and open water, and is thus a robust method. Accounting for patches of open water that are below the detection threshold of even $1 \mathrm{~m}$ resolution imagery and investigating the effect of wet tundra soil on albedo could further improve the model. Given the spread of the SWC-albedo relationship, it could best be used to estimate specific ranges of SWC, i.e., grouping Landsat pixels with SWC of 100\%-80\%, 60\%-40\%, and so on. The estimated SWC could further be linked to our knowledge of the size distribution of water bodies to estimate the number of water bodies smaller than $10^{4} \mathrm{~m}^{2}$ in a certain area.

Products like the MOD44W are invaluable for their use in regional climate and ecosystem models due to their extensive coverage. Subpixel information allows to assess the uncertainty of such coarse-resolution products and should include not only the surface water fraction but also the water body size distribution. Direct coupling of high-resolution water body maps with $1 \mathrm{~km}$ or more resolution data, however, would increase the border pixel problem that we already observed at the Landsat scale [21]. Large-scale active and passive microwave as well as optical and infrared measurements have been successfully used to estimate subpixel water cover compared with Landsat-scale maps of open water $[21,22,77]$. A nested downscaling approach could involve stacking regression functions in a two-step scaling approach from high-resolution to Landsat-based mapping and from Landsat-based mapping to coarser products. 


\section{Conclusions}

This study assessed (i) water body distributions across scales and (ii) the potential of Landsat surface albedo to show the subpixel fraction of open water cover (SWC) in three Arctic tundra wetlands in the Canadian High Arctic, Northern Russia and Alaska. Water bodies were mapped using optical and radar satellite data with spatial resolutions of $4 \mathrm{~m}$ or better, Landsat-5 TM imagery at $30 \mathrm{~m}$ and the MODIS water mask (MOD44W) at $250 \mathrm{~m}$ spatial resolution.

Water bodies at all three sites were dominated in number by ponds, i.e., water bodies with a surface area smaller than $10^{4} \mathrm{~m}^{2}$, but dominated in area by a few large lakes. At all sites ponds represented over $95 \%$ of the total water body number. Abundance of ponds, however, did not display linearly on a log-log plot as assumed in previous studies but showed a flattened lower tail instead. Landsat- and MODIS-based water body mapping lead to the truncation of the lower tail. Size distributions could then be mistaken for power-law distributed data, which would largely overestimate the number of small water bodies.

Landsat mixed pixels with a SWC between $95 \%$ and $5 \%$ showed albedo values of 0.07 to 0.12 for polygonal and wet tundra, and 0.04 to 0.07 for a drained, vegetated thermokarst basin. Landsat mixed pixels showed a strong linear relationship between albedo and SWC for these distinct terrain types. The best performance with a standard deviation of $21 \%$ SWC was obtained at the polygonal tundra site in Northern Russia where sub-meter resolution mapping of open water surfaces provided the most accurate SWC and the spectral contrast between open water and tundra was highest. Between-site variation ranged between $10 \%$ and 50\% SWC. Estimation of SWC with Landsat surface albedo proved to be a robust approach in the investigated Arctic tundra wetlands, but its applicability in other Arctic regions requires further investigation.

The quality of both water body distributions as well as SWC estimates relied on the detail of the high-resolution water body map. In this study, best results were obtained with spatial resolutions of $2 \mathrm{~m}$ or better. Decreasing resolution not only lead to the omission of small water bodies but also resulted in local overestimation of water surface area when clusters of small water bodies were merged into single larger water bodies.

This study presents an example of a remote sensing based multi-scale inventory of water bodies in Arctic tundra wetlands. Its results can be used as a baseline to better represent small water bodies of Arctic wet tundra environments in regional as well as global ecosystem and climate models.

\section{Acknowledgments}

This work was supported by the Heinrich Boell Foundation through a stipend awarded to Sina Muster and the Helmholtz Association through a grant (VH-NG 203) awarded to Julia Boike. We are grateful for the generous logistical support from Polar Continental Shelf Project (PI K.L. Young). We thank Britta Kattenstroth, Ute Wollschläger and Torsten Sachs for collecting data in the field. We thank Marcel Buchhorn for the estimations of the BRDF effect on the albedo of tundra vegetation. Measurements have been carried out with the AWI ManTIS (Manual Transportable Instrument for Spherical BRDF observations) goniometer during the GOA-ECI-Yamal 2011 expedition. We thank Arnaud Temme for

a critical review of the manuscript. TerraSAR-X imagery was provided by the German Space Agency (DLR) (Project HYD0546) and pre-processed to intensity images by GAMMA Remote Sensing and 
Consulting (AG). KOMPSAT data were provided by the European Space Agency to the ACCOnet Project (International Polar Year AO Project 4133). The Landsat-5 TM data and the MODIS water mask (MOD44W) were obtained through the online Data Pool at the NASA Land Processes Distributed Active Archive Center (LP DAAC), USGS/Earth Resources Observation and Science (EROS) Center, Sioux Falls, South Dakota (https://lpdaac.usgs.gov).

\section{References}

1. Walker, D.; Raynolds, M.; Daniëls, F.; Einarsson, E.; Elvebakk, A.; Gould, W.; Katenin, A.; Kholod, S.; Markon, C.; Melnikov, E.; et al. The circumpolar Arctic vegetation map. J. Veg. Sci. 2005, 16, 267-282.

2. Tarnocai, C.; Canadell, J.; Schuur, E.; Kuhry, P.; Mazhitova, G.; Zimov, S. Soil organic carbon pools in the northern circumpolar permafrost region. Glob. Biogeochem. Cy. 2009, 23, doi:10.1029/2008GB003327.

3. McGuire, A.; Anderson, L.; Christensen, T.; Dallimore, S.; Guo, L.; Hayes, D.; Heimann, M.; Lorenson, T.; Macdonald, R.; Roulet, N. Sensitivity of the carbon cycle in the Arctic to climate change. Ecol. Monogr. 2009, 79, 523-555.

4. Chapin III, F.S.; McGuire, A.D.; Randerson, J.; Pielke, R.; Baldocchi, D.; Hobbie, S.E.; Roulet, N.; Eugster, W.; Kasischke, E.; Rastetter, E.B. Arctic and boreal ecosystems of western North America as components of the climate system. Glob. Chang. Biol. 2000, 6, 211-223.

5. Avis, C.A.; Weaver, A.J.; Meissner, K.J. Reduction in areal extent of high-latitude wetlands in response to permafrost thaw. Nat. Geosci. Lett. 2011, 4, 444-448.

6. Jorgenson, M.; Racine, C.; Walters, J.; Osterkamp, T. Permafrost degradation and ecological changes associated with a warmingclimate in central Alaska. Clim. Chang. 2001, 48, 551-579.

7. Walter, K.; Zimov, S.; Chanton, J.; Verbyla, D.; Chapin, F. Methane bubbling from Siberian thaw lakes as a positive feedback to climate warming. Nature 2006, 443, 71-75.

8. Yoshikawa, K.; Hinzman, L.D. Shrinking thermokarst ponds and groundwater dynamics in discontinuous permafrost near Council, Alaska. Permafr. Periglac. Process. 2003, 14, 151-160.

9. Smith, L.; Sheng, Y.; MacDonald, G.; Hinzman, L. Disappearing Arctic lakes. Science 2005, $308,1429$.

10. Smol, J.P.; Douglas, M.S.V. Crossing the final ecological threshold in high Arctic ponds. Proc. Natl. Acad. Sci. USA 2007, 104, 12395-12397.

11. Emmerton, C.; Lesack, L.; Marsh, P. Lake abundance, potential water storage, and habitat distribution in the Mackenzie River Delta, western Canadian Arctic. Water Resour. Res. 2007, 43, W05419, doi:10.1029/2006WR005139.

12. Grosse, G.; Romanovsky, V.; Walter, K.; Morgenstern, A.; Lantuit, H.; Zimov, S. Distribution of Thermokarst Lakes and Ponds at Three Yedoma Sites in Siberia. In Proceedings of the Ninth International Conference on Permafrost, Fairbanks, AK, USA, 29 June-3 July 2008; pp. 551-556.

13. Muster, S.; Langer, M.; Heim, B.; Westermann, S.; Boike, J. Subpixel heterogeneity of ice-wedge polygonal tundra: A multi-scale analysis of land cover and evapotranspiration in the Lena River Delta, Siberia. Tellus B 2012, 64, 17301, doi: 10.3402/tellusb.v64i0.17301. 
14. Laurion, I.; Vincent, W.; MacIntyre, S.; Retamal, L.; Dupont, C.; Francus, P.; Pienitz, R. Variability in greenhouse gas emissions from permafrost thaw ponds. Limnol. Oceanogr. 2010, 55, 115-133.

15. Abnizova, A.; Siemens, J.; Langer, M.; Boike, J. Small ponds with major impact: The relevance of ponds and lakes in permafrost landscapes to carbon dioxide emissions. Glob. Biogeochem. Cy. 2012, 26, 1-9.

16. Lehner, B.; Döll, P. Development and validation of a global database of lakes, reservoirs and wetlands. J. Hydrol. 2004, 296, 1-22.

17. Frey, K.; Smith, L. How well do we know Northern land cover? Comparison of four global vegetation and wetland products with a new ground-truth database for West Siberia. Glob. Biogeochem. Cy. 2007, 21, 1-25.

18. Ozesmi, S.; Bauer, M. Satellite remote sensing of wetlands. Wetl. Ecol. Manag. 2002, 10, 381-402.

19. Brown, L.; Young, K. Assessment of three mapping techniques to delineate lakes and ponds in a Canadian High Arctic wetland complex. Arctic 2009, 59, 283-293.

20. Pflugmacher, D.; Krankina, O.; Cohen, W.; Friedl, M.; Sulla-Menashe, D.; Kennedy, R.; Nelson, P.; Loboda, T.; Kuemmerle, T.; Dyukarev, E.; et al. Comparison and assessment of coarse resolution land cover maps for Northern Eurasia. Remote Sens. Environ. 2011, 115, 3539-3553.

21. Weiss, D.; Crabtree, R. Percent surface water estimation from MODIS BRDF 16-day image composites. Remote Sens. Environ. 2011, 115, 2035-2046.

22. Watts, J.; Kimball, J.; Jones, L.; Schroeder, R.; McDonald, K. Satellite Microwave remote sensing of contrasting surface water inundation changes within the Arctic-Boreal Region. Remote Sens. Environ. 2012, 127, 223-236.

23. Hope, A. Estimating lake area in an Arctic landscape using linear mixture modelling with AVHRR data. Int. J. Remote Sens. 1999, 20, 829-835.

24. Olthof, I.; Fraser, R. Mapping northern land cover fractions using Landsat ETM+. Remote Sens. Environ. 2007, 107, 496-509.

25. Olthof, I.; Latifovic, R.; Pouliot, D. Circa-2000 Northern Land Cover of Canada; Government of Canada, Natural Resources Canada, Earth Sciences Sector: Sherbrooke, QC, Canada, 2008.

26. Goswami, S.; Gamon, J.; Tweedie, C. Surface hydrology of an arctic ecosystem: Multiscale analysis of a flooding and draining experiment using spectral reflectance. J. Geophys. Res. 2011, 116, G00I07.

27. Idso, S.; Jackson, R.; Reginato, R.; Kimball, B.; Nakayama, F. The dependence of bare soil albedo on soil water content. J. Appl. Meteorol. 1975, 14, 109-113.

28. Jackson, R.; Idso, S.; Reginato, R. Calculation of evaporation rates during the transition from energy-limiting to soil-limiting phases using albedo data. Water Resour. Res. 1976, 12, 23-26.

29. Fetterer, F.; Untersteiner, N. Observations of melt ponds on Arctic sea ice. J. Geophys. Res. 1998, 103, 24821-24835.

30. Eicken, H.; Grenfell, T.; Perovich, D.; Richter-Menge, J.; Frey, K. Hydraulic controls of summer Arctic pack ice albedo. J. Geophys. Res. 2004, 109, doi: 10.1029/2003JC001989. 
31. Young, K.; Assini.; J., Abnizova, A.; Miller, E. Snowcover and melt characteristics of upland/lowland terrain: Polar Bear Pass, Bathurst Island, Nunavut, Canada. Hydrol. Res. 2012, 28, doi:10.2166/nh.2012.083.

32. Woo, M.; Young, K. High Arctic wetlands: Their occurrence, hydrological characteristics and sustainability. J. Hydrol. 2006, 320, 432-450.

33. Brown, J.; Miller, P.; Tieszen, L.; Bunnell, F. An Arctic Ecosystem: The Coastal Tundra at Barrow, Alaska; Dowden Hutchinson \& Ross, Inc.: Stroudsburg, PA, USA, 1980.

34. Hinkel, K.; Eisner, W.; Bockheim, J.; Nelson, F.; Peterson, K.; Dai, X. Spatial extent, age, and carbon stocks in drained thaw lake basins on the Barrow Peninsula, Alaska. Arct. Antarct. Alp. Res. 2003, 35, 291-300.

35. Smith, S.; Burgess, M. A Digital Database of Permafrost Thickness in Canada; National Snow and Ice Data Cente: Boulder, CO, USA, 2002.

36. Grigoriev, N. The temperature of permafrost in the Lena Delta Basin: Deposit conditions and properties of the permafrost in Yakutia (in Russian). Yakutsk 1960, 2, pp. 97-101.

37. Brown, J.; Johnson, P. Pedo-Ecological Investigations, Barrow, Alaska; Technical Report, DTIC Document; CRREL: Hanover, NH, USA, 1965.

38. Abnizova, A.; Young, K.; Lafreniere, M. Pond hydrology and dissolved carbon dynamics 1 at Polar Bear Pass wetland, Bathurst Island, Nunavut. Ecohydrology 2012, doi:10.1002/eco.1323.

39. Boike, J.; Kattenstroth, B.; Abramova, K.; Bornemann, N.; Chetverova, A.; Fedorova, I.; Fröb, K.; Grigoriev, M.; Grüber, M.; Kutzbach, L.; et al. Baseline characteristics of climate, permafrost, and land cover from a new permafrost observatory in the Lena River Delta, Siberia (1998 to 2011). Biogeosci. Discuss. 2012, 9, 13627-13684.

40. Hinkel, K.; Nelson, F. Spatial and temporal patterns of active layer thickness at Circumpolar Active Layer Monitoring (CALM) sites in northern Alaska, 1995-2000. J. Geophys. Res. 2003, 108, doi:10.1029/2001JD000927.

41. Young, K.; Labine, C. Summer hydroclimatology of an extensive low-gradient wetland: Polar Bear Pass, Bathurst Island, Nunavut, Canada. Hydrol. Res. 2010, 41, 492-502.

42. Liljedahl, A.; Hinzman, L.; Harazono, Y.; Zona, D.; Tweedie, C.; Hollister, R.; Engstrom, R.; Oechel, W. Nonlinear controls on evapotranspiration in Arctic coastal wetlands. Biogeosciences 2011, 8, 3375-3389.

43. Carroll, M.; Townshend, J.; DiMiceli, C.; Noojipady, P.; Sohlberg, R. A new global raster water mask at 250 m resolution. Int. J. Digit. Earth 2009, 2, 291-308.

44. Werner, C.; Wegmüller, U.; Strozzi, T.; Wiesmann, A. Gamma SAR and Interferometric Processing Software. In Proceedings of the ERS-ENVISAT Symposium, Gothenburg, Sweden, 16-20 October 2000; pp. 16-20.

45. Fritz, T. TerraSAR-X Level $1 b$ Product Format Specification; Technical Report, TX-GS-DD-3307; DLR: Oberpfaffenhofen, Germany, 2007.

46. Wegmuller, U. Automated Terrain Corrected SAR Geocoding. In Proceedings of the IEEE 1999 International Geoscience and Remote Sensing Symposium, IGARSS'99, Hamburg, Germany, 28 June-2 July 1999; Volume 3, pp. 1712-1714. 
47. Canada, G. Canadian Digital Elevation Data, Level 1 (CDED1), version 1.0; Natural Resources Canada, Geomatics Canada: Sherbrooke, QC, Canada, 2006.

48. Shi, Z.; Fung, K. A Comparison of Digital Speckle Filters. In Proceedings of the IEEE 1994 International Geoscience and Remote Sensing Symposium: Surface and Atmospheric Remote Sensing: Technologies, Data Analysis and Interpretation, IGARSS'94, Pasadena, CA, USA, 8-12 August 1994; Volume 4, pp. 2129-2133.

49. Chavez, P. Image-based atmospheric corrections-revisited and improved. Photogramm. Eng. Remote Sensing 1996, 62, 1025-1035.

50. Chander, G.; Markham, B.; Helder, D. Summary of current radiometric calibration coefficients for Landsat MSS, TM, ETM+, and EO-1 ALI sensors. Remote Sens. Environ. 2009, 113, 893-903.

51. Chavez, P. An improved dark-object subtraction technique for atmospheric scattering correction of multispectral data. Remote Sens. Environ. 1988, 24, 459-479.

52. Thuillier, G.; Hersé, M.; Labs, D.; Foujols, T.; Peetermans, W.; Gillotay, D.; Simon, P.; Mandel, H. The solar spectral irradiance from 200 to $2400 \mathrm{~nm}$ as measured by the SOLSPEC spectrometer from the ATLAS and EURECA missions. Solar Phys. 2003, 214, 1-22.

53. Carroll, M. Personal communation. 1 February 2013.

54. Braud, D.; Feng, W. Semi-Automated Construction of the Louisiana Coastline Digital Land/Water Boundary Using Landsat Thematic Mapper Satellite Imagery; Louisiana Applied and Educational Oil Spill Research and Development Program (OSRADP), Technical Report 97-002; Louisiana State University: Baton Rouge, LA, USA, 1998.

55. Frazier, P.; Page, K. Water body detection and delineation with Landsat TM data. Photogramm. Eng. Remote Sensing 2000, 66, 1461-1467.

56. Roach, J.K.; Griffith, B.; Verbyla, D. Comparison of three methods for long-term monitoring of boreal lake area using Landsat TM and ETM+ imagery. Can. J. Remote Sens. 2012, 38, 427-440.

57. Ramsey, E., III.; Laine, S. Comparison of Landsat Thematic Mapper and high resolution photography to identify change in complex coastal wetlands. J. Coast. Res. 1997, 13, 281-292.

58. Brest, C.L.; Goward, S. Deriving surface albedo measurements from narrow band satellite data. Int. J. Remote Sens. 1987, 8, 351-367.

59. Duguay, C.; Ledrew, E. Estimating surface reflectance and albedo from Landsat-5 Thematic Mapper over rugged terrain. Photogramm. Eng. Remote Sensing 1992, 58, 551-558.

60. Liang, S. Narrowband to broadband conversions of land surface albedo I: Algorithms. Remote Sens. Environ. 2000, 76, 213-238.

61. Buchhorn, M. Personal communation. 13 February 2013.

62. Hamilton, S.; Melack, J.; Goodchild, M.; Lewis, W. Estimation of the Fractal Dimension of Terrain from Lake Size Distributions. In Lowland Floodplain Rivers: Geomorphological Perspectives; Carling, P.A., PettsWiley, G.E., Eds.; John Wiley \& Sons.: West Sussex, UK, 1992; pp. 145-163.

63. Downing, J.; Prairie, Y.; Cole, J.; Duarte, C.; Tranvik, L.; Striegl, R.; McDowell, W.; Kortelainen, P.; Caraco, N.; Melack, J.; et al. The global abundance and size distribution of lakes, ponds, and impoundments. Limnol. Oceanogr. 2006, 51, 2388-2397.

64. Seekell, D.; Pace, M. Does the Pareto distribution adequately describe the size-distribution of lakes? Limnol. Oceanogr. 2011, 56, 350-356. 
65. McDonal, C.P.; Rover, J.A.; Stets, E.G.; Striegl, R.G. The regional abundance and size distribution of lakes and reservoirs in the United States and implications for estimates of global lake extent. Limnol. Oceanogr. 2012, 57, 597-606.

66. Seekell, D.A.; Pace, M.L.; Tranvik, L.J.; Verpoorter, C. A fractal-based approach to lake size distributions. Geophys. Res. Lett. 2013, doi:10.1002/grl.50139.

67. Verpoorter, C.; Kutser, T.; Tranvik, L. Automated mapping of water bodies using Landsat multispectral data. Limnol. Oceanogr. Methods 2012, 10, 1037-1050.

68. Brown, J. Tundra soils formed over ice wedges, northern Alaska. Soil Sci. Soc. Am. J. 1967, 31, 686-691.

69. Bowling, L.; Kane, D.; Gieck, R.; Hinzman, L.; Lettenmaier, D. The role of surface storage in a low-gradient Arctic watershed. Water Resour. Res. 2003, 39, 1087, doi: 10.1029/2002WR001466.

70. Katsaros, K.; Mcmurdie, L.; Lind, R.; DeVault, J. Albedo of a water surface, spectral variation, effects of atmospheric transmittance, sun angle and wind speed. J. Geophys. Res. 1985, 90, 7313-7321.

71. Scott Pegau, W.; Paulson, C. The albedo of Arctic leads in summer. Ann. Glaciol. 2001, 33, 221-224.

72. Payne, R. Albedo of the sea surface. J. Atmos. Sci. 1972, 29, 959-970.

73. Nunez, M.; Davies, J.; Robinson, P. Surface albedo at a tower site in Lake Ontario. Bound.-Layer Meteorol. 1972, 3, 77-86.

74. Cogley, J. The albedo of water as a function of latitude. Mon. Wea. Rev. 1979, 107, 775-781.

75. Langer, M.; Westermann, S.; Muster, S.; Piel, K.; Boike, J. The surface energy balance of a polygonal tundra site in Northern Siberia-Part 1: Spring to fall. The Cryosphere 2011, 5, 151-171.

76. Lucht, W.; Hyman, A.; Strahler, A.; Barnsley, M.; Hobson, P.; Muller, J. A comparison of satellite-derived spectral albedos to ground-based broadband albedo measurements modeled to satellite spatial scale for a semidesert landscape. Remote Sens. Environ. 2000, 74, 85-98.

77. Prigent, C.; Matthews, E.; Aires, F.; Rossow, W. Remote sensing of global wetland dynamics with multiple satellite data sets. Geophys. Res. Lett. 2001, 28, 4631-4634.

(c) 2013 by the authors; licensee MDPI, Basel, Switzerland. This article is an open access article distributed under the terms and conditions of the Creative Commons Attribution license (http://creativecommons.org/licenses/by/3.0/). 